\title{
Role of the nitric oxide on rosuvastatin-induced relaxation of the calf cardiac vein during cooling
}

\author{
Guresir MS, Nurullahoglu Atalik KE \\ Department of Pharmacology, Faculty of Meram Medicine, University of Necmettin Erbakan, Konya, Turkey. \\ esraatalik@hotmail.com
}

Abstract: Objective: 3 -hydroxy-3-methylglutaryl coenzyme A (HMG-CoA) reductase inhibitors including rosuv-
astatin do not only lower plasma cholesterol but also have non-cholesterol lowering effects on the vessel wall,
which decrease cardiovascular complications. The aim of the present study was to evaluate the effect of cooling
(to $28{ }^{\circ} \mathrm{C}$ ) on the vasodilatation induced by rosuvastatin $\left(10^{-9}-3 \times 10^{-4} \mathrm{M}\right)$ on serotonin-pre-contracted calf cardiac
vein and the role of nitric oxide in these effects.
Material and methods: Ring preparations of veins obtained from calf hearts were suspended in organ baths
containing $25 \mathrm{ml}$ of Krebs-Henseleit solution, maintained at $37^{\circ} \mathrm{C}$ and continuously gassed with $95 \% \mathrm{O}_{2}-5 \%$
$\mathrm{CO}_{2}$. After a resting period, preparations were contracted with serotonin $\left(10^{-6} \mathrm{M}\right)$ at $37^{\circ} \mathrm{C}$.
Results: Rosuvastatin produced concentration-dependent relaxation of calf cardiac vein precontracted with sero-
tonin $\left(10^{-6} \mathrm{M}\right)$. During cooling, the plC $\mathrm{C}_{50}$ value, but not the maximal response, to rosuvastatin was significantly
higher than at $37^{\circ} \mathrm{C}$. Cooling to $28{ }^{\circ} \mathrm{C}$ in the presence of $\mathrm{N}^{\mathrm{G}}$-nitro-L-arginine methyl ester (L-NAME, $10^{-4} \mathrm{M}$ )
decreased the plC $\mathrm{C}_{50}$ values to rosuvastatin.
Conclusion: The results of the present study suggested that nitric oxide played an essential role in the cooling-
induced changes of rosuvastatin in calf cardiac vein (Fig. 1, Ref. 23$)$. Text in PDF www.elis.sk.
Key words: cardiac vein, cooling, nitric oxide, rosuvastatin.

It is well known that endothelium plays a crucial role in the regulation of cardiovascular homeostasis through the release of vasoactive factors such as nitric oxide. Nitric oxide directly activates soluble guanylate cyclase (GC) in vascular smooth muscle cells and increases intracellular cyclic GMP production, resulting in vasodilation (1). Nitric oxide-mediated vascular tone or reactivity can be modulated or inhibited during different stages of cooling. It is generally accepted that cooling potentiates vasoconstrictor responsiveness in cutaneous vessels and decreases this responsiveness in deep vessels, such as rabbit carotid arteries (2), human coronary arteries (3), and rat pulmonary arteries and thoracic aortae (4). Extensive studies have focused on the involvement of endothelial nitric oxide in cooling-induced vasodilation. Although the cooling-induced effect on deep vessels was primarily reported in 'in vitro isolated vessels', there are still inconsistencies regarding the role of nitric oxide in cooling-induced vasodilation.

Several studies have been performed using varying degrees of hypothermia, different species and types of vessels, and multiple agonists to study the nitric oxide-dependent relaxation ef-

Department of Pharmacology, Faculty of Meram Medicine, University of Necmettin Erbakan, Konya, Turkey

Address for correspondence: K. Esra Nurullahoglu Atalik, Department of Pharmacology, Faculty of Meram Medicine, University of Necmettin Erbakan, Konya, 42080, Turkey. Fax: +90.332 .2237124$

Acknowledgements: We are grateful to Abdi İbrahim Drug Industry (Istanbul, Turkey) for supplying us with rosuvastatin. fects of hyperthermia on vascular reactivity. Regardless, there are still inconsistencies regarding the role of nitric oxide in coolinginduced vasorelaxation. In rat aorta, cooling augmented nitric oxide-dependent relaxation (16), and mild hypothermia $\left(34{ }^{\circ} \mathrm{C}\right)$ attenuated Phenylephrine-mediated contractions by increasing nitric oxide production (19). In contrast, moderate cooling $\left(24^{\circ} \mathrm{C}\right)$ induced vasodilation in human saphenous veins independently of the endothelium, and this response was unrelated to the release of nitric oxide (26).

Rosuvastatin is a member of the statin family with hepatoselective uptake and modest liver metabolism, long half-life period, water-solubility and more potency in lipid lowering than other statins (8); further studies have reported anti-inflammatory effect (9), antioxidative stress (10), upregulation of endothelial nitric oxide and lipid lowering action $(11,12)$.

The purpose of this study was to determine the effects of cooling $\left(28^{\circ} \mathrm{C}\right)$ on vascular smooth muscle responses to rosuvastatin in calf cardiac vein, analyzing the role of nitric oxide in these effects. These vessels were selected because these are easily accessible vessels and are appropriate for studying the direct effect of agents on the vascular smooth muscle. Therefore, 5-HT was used as contractile agent.

\section{Methods}

\section{Tissue preparations}

Calf hearts were obtained from a slaughterhouse and immediately placed in Krebs-Henseleit solution. Segments of the great 
cardiac vein were removed and cut into rings of $2.5 \mathrm{~mm}$ in length. Care was taken not to damage the endothelium. Each ring was mounted in $25 \mathrm{ml}$ organ baths containing Krebs-Henseleit Solution (KHS), aerated with $95 \% \mathrm{O}_{2}$ and $5 \% \mathrm{CO}_{2}$. KHS was composed of (mM): $\mathrm{NaCl} 119, \mathrm{KCl} 4.70, \mathrm{MgSO}_{4} 1.50, \mathrm{KH}_{2} \mathrm{PO}_{4} 1.20, \mathrm{CaCl}_{2}$ 2.50, $\mathrm{NaHCO}_{3} 25$, Glucose 11 .

Changes in isometric tension were recorded by a force-displacement transducer (BIOPAC MP36, Santa Barbara, California, USA) connected through amplifiers to a ITBS08 Integrated Tissue Bath System (Commat, Ankara, Turkey). The tissues were allowed to equilibrate for $60 \mathrm{~min}$ under a resting tension of $1 \mathrm{~g}$ with repeated washing every $15 \mathrm{~min}$.

\section{Experimental design}

The endothelial cell integrity was determined in each ring before all experiments. Relaxation responses to acetylcholine (ACh, 10-6 M) in rings pre-constricted with 5-hydroxytryptamine (5-HT, 10-6 M) were used to test endothelial cell integrity. Preparations, which was relaxed by $>70 \%$ of the 5 -HT-induced tone after addition of Ach, were considered to have undamaged endothelium. Thereafter, experimental procedures were performed as describe below.

After the stabilization period, cardiac vein preparations were contracted with 10-6 M 5-HT. After the contraction had reached a steady state, rosuvastatin was added to the organ bath cumulatively $(10-9-3 \times 10-4 \mathrm{M})$ at $37{ }^{\circ} \mathrm{C}$. The maximal 5-HT contraction was used as a standard, by which subsequent responses of the tissue could be expressed (as a percentage of this contraction).

After the first concentration-response curve was completed, preparations were washed and allowed to reestablish a resting tension. After the contractile responses to 5-HT, the temperature was changed from $37-28{ }^{\circ} \mathrm{C}$ (cooling). Cooling was rapidly achieved

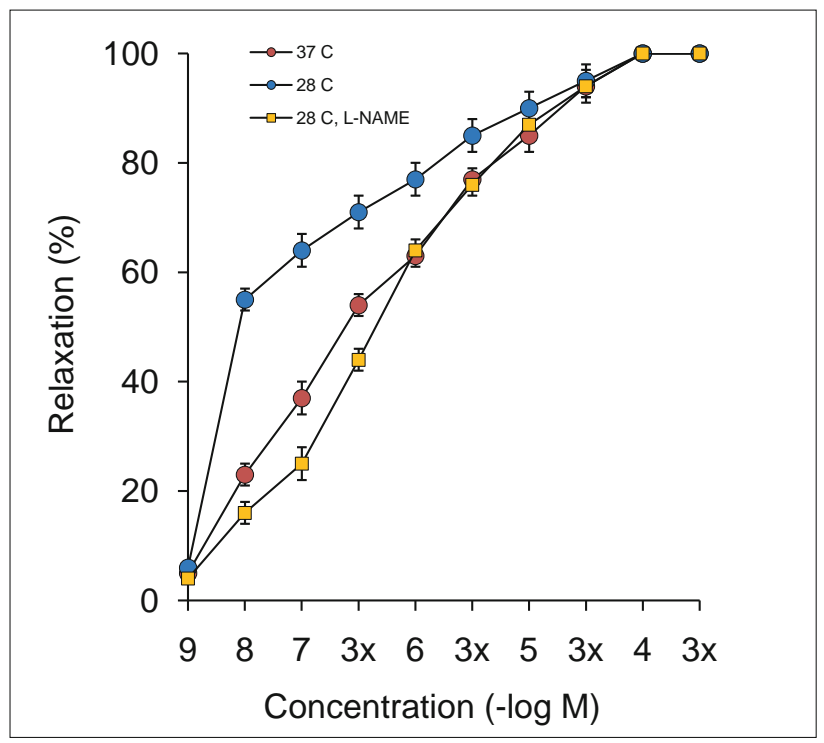

Fig. 1. Rosuvastatin concentration-response curves of calf cardiac vein precontracted with 5-HT at $37.28^{\circ} \mathrm{C}$ and $28^{\circ} \mathrm{C}$ in the presence of $\mathrm{L}$ NAME. Each point is the mean \pm SEM of six experiments. and preparations were allowed to equilibrate at this temperature for $30 \mathrm{~min}$ before a second concentration-response curve was determined for rosuvastatin. Rosuvastatin was prepared daily and added to the organ bath cumulatively.

The influence of nitric oxide on relaxations to rosuvastatin was specifically addressed by pre-treating the rings with the nitric oxide synthase inhibitor NG nitro-L-arginine methlyl esther (LNAME, 10-4 M). Again, after the contractile response to 5-HT, the temperature was changed from 37 to $28^{\circ} \mathrm{C}$. The tissues were allowed to equilibrate at $28^{\circ} \mathrm{C}$ for $30 \mathrm{~min}$. L-NAME was added to the organ bath $20 \mathrm{~min}$ before concentration-response curves were obtained. Endothelium was not denuded because only the role of endothelial NO was examined in this study.

\section{Statistical analysis}

Relaxation responses to rosuvastatin were expressed as percentages of the 5-HT (10-6 M) induced contraction. Concentrations of rosuvastatin causing $50 \%$ of the maximal response (IC50) were calculated from each individual concentration-response curves. Maximal responses (Emax) and pIC50 (-log IC50) values for curves obtained before and during cooling were compared by using the Student's $t$ test. Statistical significance was set at $\mathrm{p}<0.05$.

\section{Drugs}

Serotonin creatinine sulfate, NG nitro-L-arginine methlylesther, acetycholine chloride (all dissolved in distilled water) and rosuvastatin (dissolved in dimethyl sulphoxide; DMSO. The concentration of DMSO in the tissue bath was always kept below 0.4 $\%$ ) were used. Carbachol and ACh were obtained from Sigma (St. Louis, MO, USA). Rosuvastatin was kindly provided by Abdi İbrahim Drug Industry (Istanbul, Turkey).

\section{Results}

In calf cardiac vein, 5-HT $\left(10^{-6} \mathrm{M}\right)$ produced reproducible contractions and time-dependent changes were not observed in response to this agent. Cumulative addition of rosuvastatin (10${ }^{9}-3 \times 10^{-4} \mathrm{M}$ ) produced concentration-dependent relaxation of calf cardiac vein preparations precontracted with 5-HT at both 37 and $28^{\circ} \mathrm{C}$ (cooling) (Fig. 1). Compared to $37^{\circ} \mathrm{C}$, the $\mathrm{pIC}_{50}$ value of rosuvastatin was significantly lower $\left(\mathrm{pIC}_{50}=6.63 \pm 0.07\right.$ at $37^{\circ} \mathrm{C}$ and $8.10 \pm 0.01$ at $\left.28{ }^{\circ} \mathrm{C} ; \mathrm{p}<0.05\right)$ at $28^{\circ} \mathrm{C}$.

Preincubation with L-NAME $\left(10^{-4} \mathrm{M}\right)$ significantly decreased the $\mathrm{pIC}_{50}$ values to rosuvastatin during cooling $\left(\mathrm{pIC}_{50}=6.36 \pm\right.$ $0.42 ; \mathrm{p}<0.05)$.

\section{Discussion}

In the present work, we studied the effects of cooling on rosuvastatin-induced vasodilatation of calf cardiac vein, paying a special attention to the role of nitric oxide in these responses. The calf cardiac vein is easily accessible smooth muscle preparations and there is a limited information (13-16) about the effects of temperature in these vessels and the effects of cooling were generally studied with contractile agents. Furthermore, to our 
knowledge, there are no studies that analyze the effects of cooling on the rosuvastatin-induced relaxations.

The temperature utilized in this study; $28^{\circ} \mathrm{C}$, for cooling was considered to be 'moderate cooling' temperature accordingly to our previous studies $(13,17)$.

Our results indicated that at $37^{\circ} \mathrm{C}, 5$-HT-induced reproducible contractions in cardiac vein. At this temperature, rosuvastatin induced concentration-dependent vasodilatation in 5-HT-precontracted preparations. No previous data on the effects of rosuvastatin of calf cardiac vein during cooling has been published. Although statins are well known for reducing cholesterol levels, they can also produce other beneficial effects in vascular events. It is known that rosuvastatin is characterized by long half-life, water-solubility and more potency in lipid lowering than other statins. Rosuvastatin is reported to have direct neuroprotective actions, which may be more effective than other statins (18). It is reported that rosuvastatin ameliorated ischemic brain injury via mainly eNOS activation (19) and modulation of mitogen-activated protein kinases (20).

Endothelium-mediated vascular tone or reactivity can be modulated or inhibited during different stages of hypothermia. It is generally accepted that hypothermia potentiates vasoconstrictor responsiveness in cutaneous vessels and decreases this responsiveness in deep vessels, such as rabbit carotid arteries (2), human coronary arteries (3), and rat pulmonary arteries and thoracic aortae (4). Extensive studies have focused on the involvement of endothelial nitric oxide or PGI2 in hypothermia-induced vasorelaxation. Although the hypothermic effect on deep vessels was primarily reported in 'in vitro isolated vessels', there are still inconsistencies regarding the role of endothelium in hypothermiainduced vasorelaxation. Therefore, in this study, to examine the role of nitric oxide in rosuvastatin-induced relaxations during cooling, was assessed by pretreatment with the NOS inhibitor LNAME. The sensitivity to rosuvastatin was decreased by cooling in the presence of L-NAME suggesting that nitric oxide release may be stimulated under hypothermic conditions. Our results are in agreement with those reported by Chung et al (21) who have reported that hypothermia-induced vasorelaxation was significantly attenuated in the presence of L-NAME, and indomethacin, an inhibitor of cyclooxygenase, suggested that the production of nitric oxide and prostacyclin $\left(\mathrm{PGI}_{2}\right)$ in the endothelium could be increased under moderate hypothermia. Evora et al (22) demonstrated that the endothelium is sensitive to temperature variations and that the prostacyclin and nitric oxide -dependent pathways may be involved in hypothermia-induced endothelium-dependent vasorelaxation. There are limitations to directly measuring vessel production of endothelium-derived relaxation factors. For example, nitric oxide is quickly oxidized to form nitrite. To confirm the involvement of endothelium-dependent mechanisms on hypothermia-induced vasorelaxation, Fernández et al (23) demonstrated that exposure of rabbit ears and femoral arteries to hypothermia $\left(24{ }^{\circ} \mathrm{C}\right)$ increased nitrite production, an indirect indicator of nitric oxide production. In contrast, Chung et al (21) demonstrated by radioimmunoassay that cGMP is enhanced in the endothelium-intact rings at $25^{\circ} \mathrm{C}$, suggesting that moderate hypothermia stimulates the release of endothelial nitric oxide, which activates the GC-cGMP pathway in vascular smooth muscle cells and consequently relaxes vascular tone. In addition, the investigators demonstrated that the production of cAMP elicited by moderate hypothermia was significantly enhanced only in the endothelium-intact rings and not in the endothelium-denuded rings (21). Furthermore, Mustafa and Thulesius (4) reported that stepwise cooling $\left(37^{\circ} \mathrm{C}\right.$ to $\left.4{ }^{\circ} \mathrm{C}\right)$ of aortic smooth muscle induced reproducible graded relaxations that were inversely proportional to temperature. Cooling-induced relaxation was not dependent on a neural mechanism neither on the release of neurotransmitters or a cooling-released substance such as nitric oxide or CO. Cooling of pulmonary arterial and aortic smooth muscle preparations induced a graded myogenic relaxation inversely proportional to the cooling temperature. The mechanism is not dependent on local nervous or known mediators but related to a direct physicochemical effect of cooling. However, no studies have analyzed the role of nitric oxide on rosuvastatin-induced relaxation during cooling of cardiac vein.

In conclusion, the present results demonstrated for the first time that rosuvastatin induced relaxation of calf cardiac vein and also suggested that nitric oxide had a role on the decreased sensitivity to rosuvastatin during cooling.

\section{References}

1. Cohen RA, Plane F, Najibi S et al. Nitric oxide is the mediator of both endothelium-dependent relaxation and hyperpolarization of the rabbit carotid artery. Proc Natl Acad Sci USA (1997); 94: 4193-4198.

2. Mustafa S, Thulesius O. Cooling-induced carotid artery dilatation: an experimental study in isolated vessels. Stroke (2002); 33: 256-260.

3. Bodelsson M, Arneklo-Nobin B, Chester AH et al. Differential effect of hypothermia on the vascular tone and reactivity of the human coronary artery and graft vessels. J Cardiavasc Surg (1991); 32: 288-294.

4. Mustafa S, Thulesius O. Cooling is a potent vasodilator of deep vessels in the rat. Can J Physiol Pharmacol (2001); 79: 899-904.

5. Karaki H, Nagase H. Low temperature augments endothelium-dependent relaxation in isolated rat aorta. Eur J Pharmacol (1987); 142: 129-132.

6. Lagneau F, Kirstetter P, Bernard C, Marty J. Effect of mild hypothermia on the vascular actions of phenylephrine in rat aortic rings. Br J Anaesth (1999); 82: 938-940.

7. Simonet S, Bonhomme E, Fabiani JN, Verbeuren T. Temperature dependent basal tone in isolated human saphenous veins: implication of TP-receptors. Fundam Clin Pharmacol (2000); 14: 461-467.

8. McTaggart F, Buckett L, Davidson R et al. Preclinical and clinical pharmacology of Rosuvastatin, a new 3-hydroxy-3-methylglutaryl coenzyme A reductase inhibitor. Am J Cardiol (2001); 87: 28-32.

9. Gullestad L, Ueland T, Kjekshus $\mathbf{J}$ et al. The predictive value of galectin-3 for mortality and cardiovascular events in the Controlled Rosuvastatin Multinational Trial in Heart Failure (CORONA). Am Heart J (2012); 164: 878-883.

10. Grosser N, Erdmann K, Hemmerle A et al. Rosuvastatin upregulates the antioxidant defense protein heme oxygenase-1. Biochem Biophys Res Commun (2004); 325: 871-876. 


\section{$753-756$}

11. Baigent $\mathbf{C}$, Keech A, Kearney $\mathbf{P M}$ et al. Efficacy and safety of cholesterol-lowering treatment: prospective meta-analysis of data from 90,056 participants in 14 randomised trials of statins. Lancet (2005); 366: $1267-1278$.

12. Mayer C, Gruber HJ, Landl EM et al. Rosuvastatin reduces interleukin-6-induced expression of C-reactive protein in human hepatocytes in a STAT3- and C/EBP-dependent fashion. Int J Clin Pharmacol Ther (2007); 45: 319-327.

13. Atalik KE, Sahin AS, Ulusoy HB, Doğan N. The role of K+ ions on the response to carbachol of calf coronary artery and cardiac vein during cooling. Methods Find Exp Clin Pharmacol (2001); 23: 231-234.

14. Atalik KE, Sahin AS, Ulusoy HB, Doğan N. Warming and response to contractile agents in calf cardiac vein: role of the nitric oxide. Fundam Clin Pharmacol (2003); 17: 77-82.

15. Atalik KE, Sahin AS, Dogan N. Warming and response to contractile agents in calf cardiac vein: role of the $\mathrm{Ca} 2+, \mathrm{KCa} 2+$, and $\mathrm{Na}+$ ion channel blockers. Methods Find Exp Clin Pharmacol (2005); 27: 653-657.

16. Atalik KE, Kiliç M, Doğan N. Role of the nitric oxide on diazoxideinduced relaxation of the calf cardiac vein and coronary artery during cooling. Fundam Clin Pharmacol (2009); 23: 271-277.

17. Atalik KE, Şahin AS, Kiliç M, Doğan N. Role of the endothelium on the response to adrenoceptor agonists of rabbit aorta during cooling. Fundam Clin Pharmacol (2000); 14: 25-30.
18. Zacco A, Togo J, Spence K et al. 3-hydroxy-3-methylglutaryl coenzyme A reductase inhibitors protect cortical neurons from excitotoxicity. J Neurosci (2003); 23: 11104-11111.

19. Laufs U, Gertz K, Dirnagl U et al. Rosuvastatin, a new HMG-CoA reductase inhibitor, upregulates endothelial nitric oxide synthase and protects from ischemic stroke in mice. Brain Res (2002); 942: 23-30.

20. Chen J, Li D, Schaefer R, Mehta JL. Cross-talk between dyslipidemia and renin-angiotensin system and the role of LOX-1 and MAPK in atherogenesis studies with the combined use of rosuvastatin and candesartan. Atherosclerosis (2006); 184: 295-301.

21. Chung JY, Kim JE, Yoon HJ et al. Moderate hypothermia attenuates $\alpha_{1}$-adrenoceptor-mediated contraction in isolated rat aorta: The role of the endothelium. Cryobiology (2012); 65: 33-40.

22. Evora PR, Cable DG, Chua YL et al. Nitric oxide and prostacyclindependent pathways involvement on in vitro induced hypothermia, Cryobiology (2007); 54: 106-113.

23. Fernandez N, Garcia-Villalon AL, Borbujo $\mathbf{J}$ et al. Cooing effects on the histaminergic response of rabbit ear and femoral arteries: role of the endothelium. Acta Physiol Scand (1994); 151: 441-451.

Received May 15, 2013. Accepted June 26, 2014. 